\title{
Reliability Investigation for a Fleet of Load Haul Dump Machines in a Swedish Mine
}

\author{
Uday Kumar, Bengt Klefsjö \& Sven Granholm \\ Mining Equipment Engineering Department, Luleå University of Technology, \\ S-951 87 Luleå, Sweden
}

(Received 9 January 1989; accepted 3 March 1989)

\begin{abstract}
The recent trends of deployment of complex and capital intensive equipment in mines has created interest in the field of maintenance and operational reliability of this equipment. The failure consequences associated with random equipment failures have considerable influence on the total operating cost of a highly mechanized mining system. Keeping this in view, a reliability investigation was initiated for a fleet of diesel operated load-haul-dump (LHD) machines in a Swedish mine. The goal is to estimate the operational reliability of these machines, locate items or assemblies which need improvement in design to enhance the reliability and to decide the duration of optimal preventive maintenance. Failure data for one year of LHD machines are analysed using the recently developed graphical technique of total time on test (TTT) plotting. Analytical methods like Kolmogorov-Smirnov test and maximum likelihood estimation are used in the analysis. The importance of testing the reliability data for the presence of trends and serial correlation is also emphasized.
\end{abstract}

\section{INTRODUCTION AND BACKGROUND}

With increasing mechanization and automation in mines, the importance of obtaining highly reliable operating systems has recently been recognized by the mining industry. From an economic point of view, high reliability is desirable to reduce the maintenance costs of the systems. Earlier, maintenance was never considered as a major problem in mines because the

Reliability Engineering and System Safety 0951-8320/89/\$03.50 (C) 1989 Elsevier Science Publishers Ltd, England. Printed in Great Britain 
consequences of equipment failure were negligible. But the failure consequences of present day capital intensive machines cannot be ignored particularly when the mineral prices are very low. To achieve better results, further automation and mechanization of the mining operation is being considered by the Swedish mining industry and also measures are being taken to enhance the productivity and utilization of the existing resources.

During 1986, a comprehensive research program was initiated by the Swedish mining industry to study the mine operating systems in detail and to locate the possible bottle-necks in the system and suggest measures for improvement. A recent study ${ }^{1}$ of various cost elements in Swedish mines have shown that the maintenance cost both direct and indirect often constitutes $50-60 \%$ of the equipment operating cost. The indirect maintenance cost is due to the incidence of random equipment failures as these result in indirect cost of maintenance due to losses in production and forced idleness of other equipment in the operating system. The area of maintenance is identified as strategic for cost reduction in mechanized mines by the Swedish mining industry.

\subsection{The mine operating systems}

With a high degree of mechanization and partial automation, the mining operations can be conceived as a system comprising subsystems connected in series (see Fig. 1). Thus, if one unit is down and suitable standby is not available, the whole system is stopped, and the indirect cost due to losses in production due to poor reliability of subsystem is incurred. In most of the mechanized mines, drilling and blasting is the dominating method for fragmentation. When suitable fragmentation is obtained, fragmented rock mass is loaded either into trucks or dumped into orepasses using suitable loaders. The ore is crushed and transported to the ore dressing plants for sorting and enrichment.

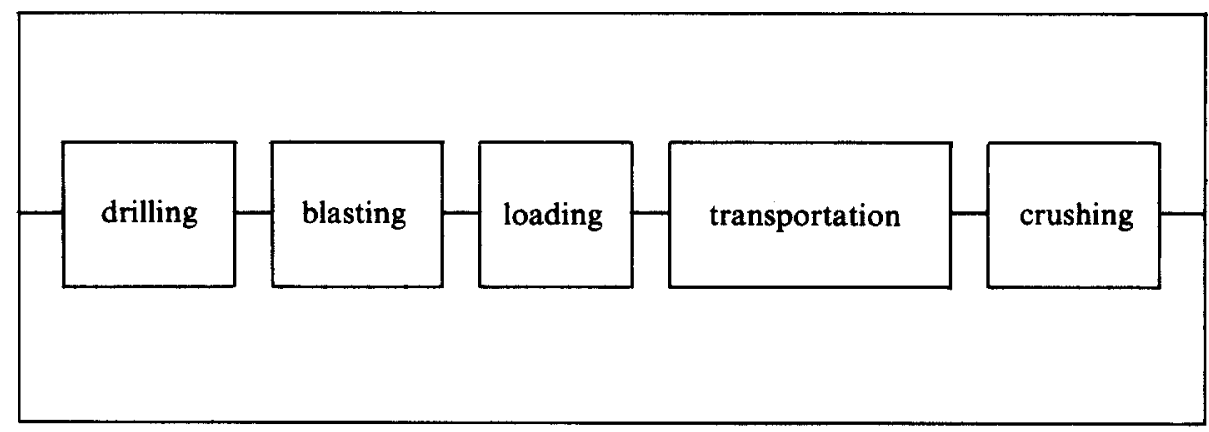

Fig. 1. A simplified diagram of a mine operating system. 


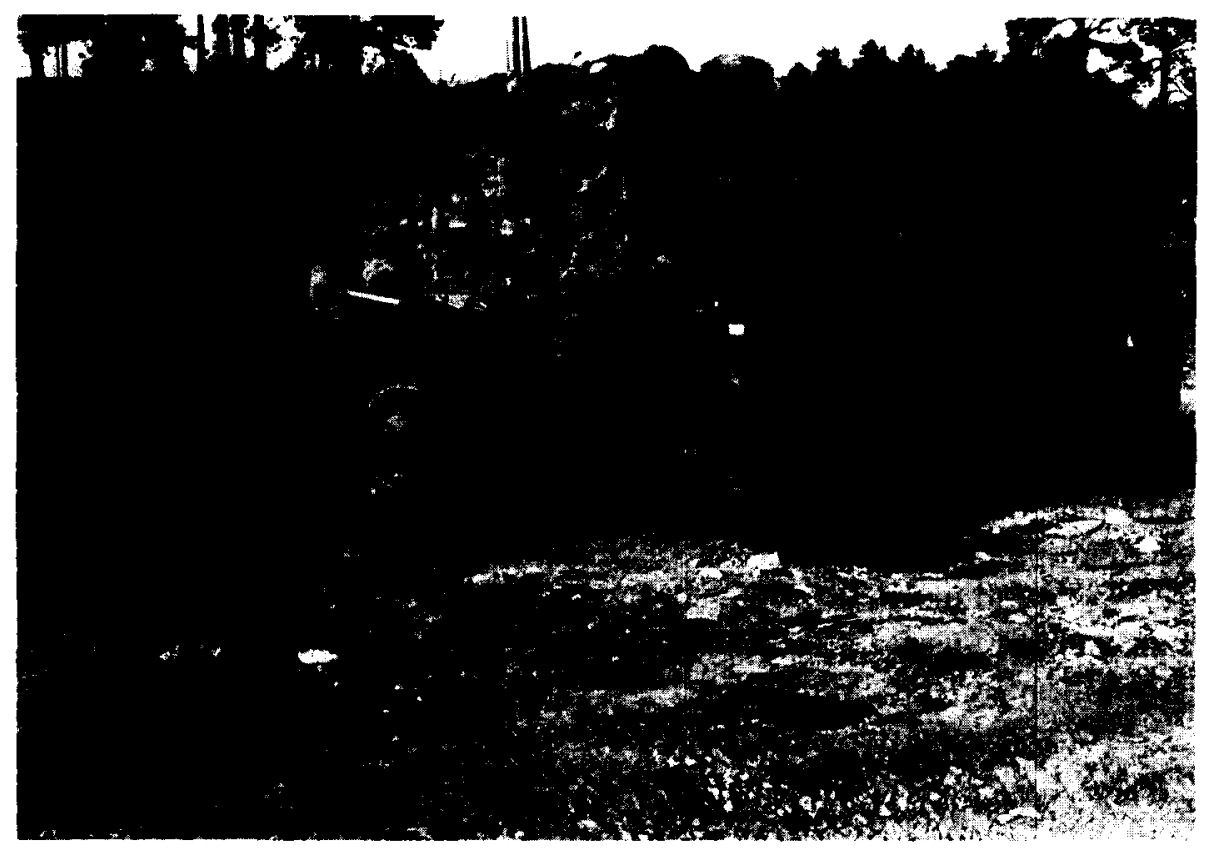

Fig. 2. An LHD machine.

\subsection{The load-haul-dump (LHD) machines}

The dominating machine for loading rock in underground mines in Sweden is the LHD machine (see Fig. 2). LHD machines are used to pick up ore or waste rock from the mining points and dump it either into trucks or orepasses depending on the distance. If the distance is more than $200 \mathrm{~m}$ or so trucks are used to transport the ore from the mining faces to main ore drawpoints. Most of the LHD machines are diesel powered but gradually electric LHDs are being introduced in Swedish mines.

The strategic location of an LHD machine in a mine operating system and its high cost of operation and maintenance motivated the selection of LHD fleet for this study. The ongoing efforts for designing an automatic LHD suitable for hard rock mining conditions provided the additional incentives to study the reliability characteristics of such machines. The goal is to identify the items, subassemblies or assemblies of these machines which need improvement in design and to formulate effective maintenance policies for such equipment to enhance the operational reliability of loading operations. For this study, the machine is considered as a system comprising many subsystems such as engine, hydraulics, transmissions, brakes, etc., connected in series as shown in Fig. 3. 


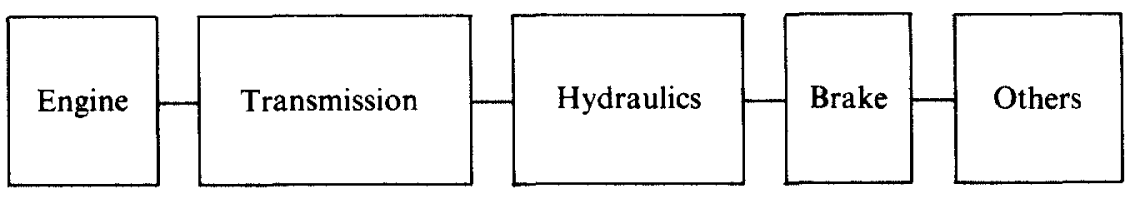

Fig. 3. A reliability block diagram of an LHD machine.

The time between successive failures (TBF) data for a period of one year were sorted and analysed. Different types of statistical distributions were examined and their parameters are estimated by the maximum likelihood (ML) method. Furthermore, TTT-plots and double TTT-plots, which are recent graphical methods, are used while analysing the TBFs and the results are compared to that obtained by the ML method. Simple graphical techniques are used to test the independent and identically distributed (iid) assumption for the data set.

\section{BASIC CONCEPTS}

\subsection{Techniques for failure data analysis}

The commonly applied failure data analysis techniques are probability plotting, hazard plotting, the method of maximum-likelihood (ML) estimation and recently developed TTT-plotting methods. In this paper we will be using the ML methods together with TTT-plots to analyse the TBFs. The ML method is versatile and can be applied to most distributions and statistical models and also to various types of data. However, this method often requires computer programs to solve the various partial differential equations. The ML method for failure data analysis is discussed extensively by Nelson. ${ }^{2}$

The technique of TTT-plotting, originally suggested by Barlow and Campo, ${ }^{3}$ is very simple to use for failure data analysis. ${ }^{4-7}$ This method, like other methods mentioned above, is also based on the assumption that the times between failures (TBF) are independently and identically distributed, so that the actual chronological orderings of the TBFs can be ignored. Thus, it is not useful to analyse a data set which has structures or is positive to the serial correlation test by using a TTT-plot. However, an important feature of these plots is that incomplete data can be analysed. Different applications of TTT-plotting have been discussed by Klefsjö. ${ }^{8,9}$ The TTTconcept is briefly presented in Appendix 1. A recent generalization of the TTT-plot is the double TTT-plot suggested by Akersten. ${ }^{10.11}$ This 
generalization which is very useful for the study of repairable systems is also briefly discussed in Appendix 1.

\subsection{Assumption of iid for the TBFs}

Since the assumption of iid is normally not valid, ${ }^{12,13}$ proper tests should be used to test for the presence of structures or trends in the failure data (the TBFs). If there is no trend in the data, the assumption of identical distribution for the TBFs under consideration is not contradicted. It is also important to test the successive interarrival times for independence by testing them for serial correlation. We will be using graphical methods for testing for presence of any trends and serial correlation in our data. A thorough discussion about the abuse of the iid assumption can be found in Ascher and Feingold. ${ }^{13}$

\section{DATA COLLECTION, SORTING AND CLASSIFICATION}

To collect information about the time between successive failures, operation and maintenance cards of a fleet of 19 LHD machines were collected for a period of one year. These cards record times to failure, the engine clock hour and the reported failures in case of operation cards, and the time to repairs and actual repairs performed in case of maintenance cards. Since it is not possible to present the time between failures (TBF) data of all the machines, only the TBF data for three machines are given in chronological order (see Appendix 2, Table B1). These machines are selected such that they are neither too old nor too new.

From the maintenance and operation cards of these machines, the TBFs for the engine, brake, transmission and hydraulic subsystems were calculated. Many times more than one subsystem has been repaired. For the purpose of this study, the failure reason was assigned only to those subsystems for which machine was stopped. For example in case of LHD A, at serial number one, the subsystems repaired are engine, hydraulics and body, but for the purpose of this study only the engine will be assigned as reason for failure and others will be treated as censored failures. Based on this, the TBFs for the subsystems are calculated. The TBFs of the engines for all the three machines are given in Appendix 2, Table B2. But the TBFs of the other subsystems namely hydraulics, brake and transmission are presented only for LHD A in Appendix 2, Table B3. Since, sometimes machines are stopped for routine maintenance purposes, the TBFs obtained due to stoppage for maintenance are classified as censored failures. Further, only the TBFs of the engines are analysed with and without censored failures using double TTT-plots. 


\section{METHODOLOGY OF DATA ANALYSIS}

\subsection{Trend analysis for the TBFs}

To explore the presence of structures in the TBFs of LHD machines and their major subsystems, the cumulative time between successive failures was plotted against the cumulative number of failures in each case. No trend or structure was observed in most of the TBFs data sets as interpreted from the linearity of the curves. An example of such a curve is shown in Fig. 4.

However the TBF data for some of the subsystems have shown the presence of structure as shown in Fig. 5, indicating that the data are not identically distributed. But in this study, we have for simplicity treated also these TBFs as having no trend. In the next section, we will show that such an assumption can lead to a wrong conclusion about the failure rate.

Further, to test the TBFs for independence, the failures data were tested for serial correlation. To test the data for serial correlation, the (i-1)th TBF were plotted against the $i$ th TBF for the various machines and subsystems. No distinct serial correlation was observed for most of the data sets as illustrated in Fig. 6.

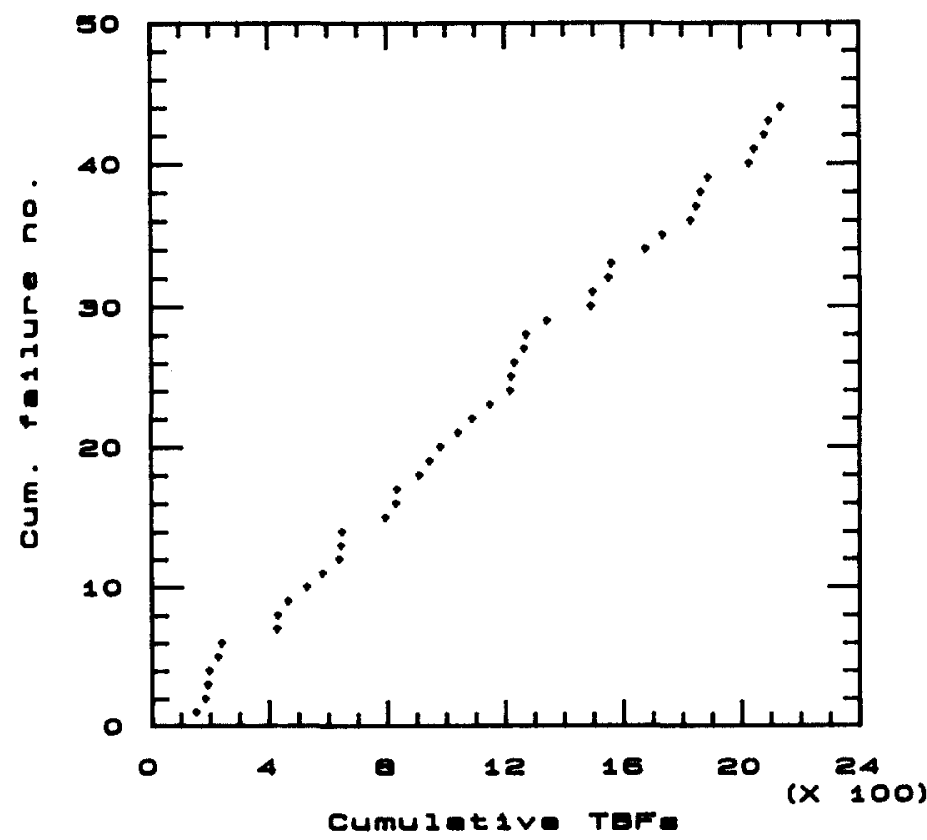

Fig. 4. Scatter plot of cumulative TBFs versus cumulative number of failures for LHD B to test the presence of trend. 


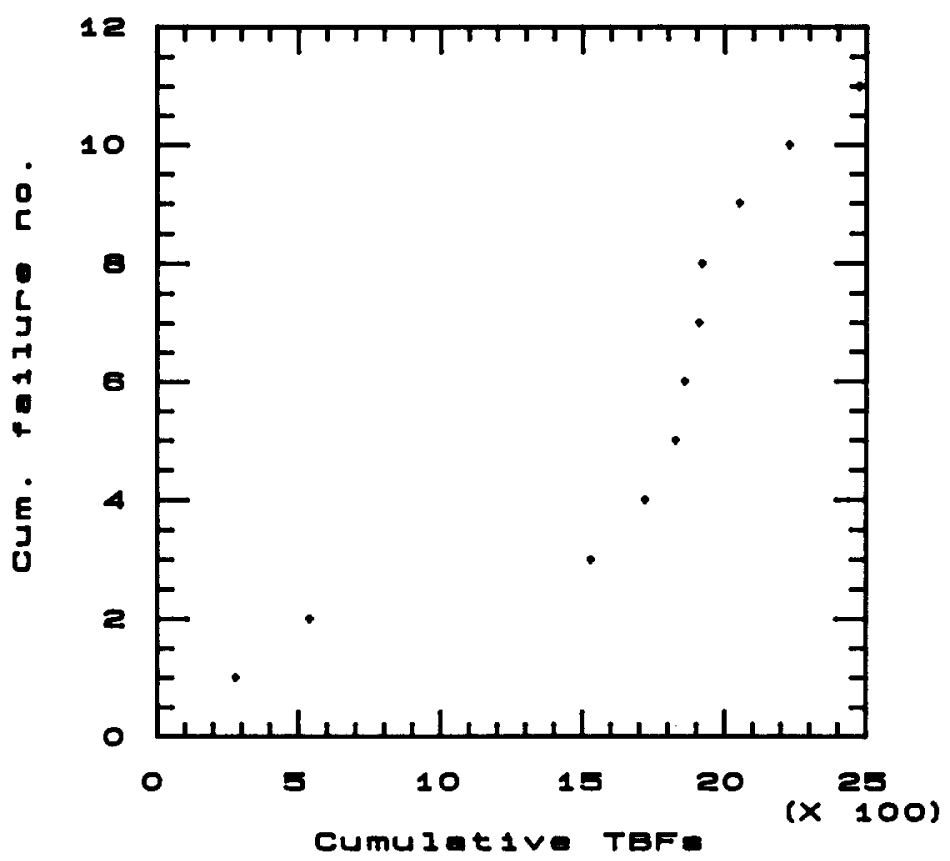

Fig. 5. Exhibiting the presence of trend in the TBFs of hydraulic subsystem of LHD A.

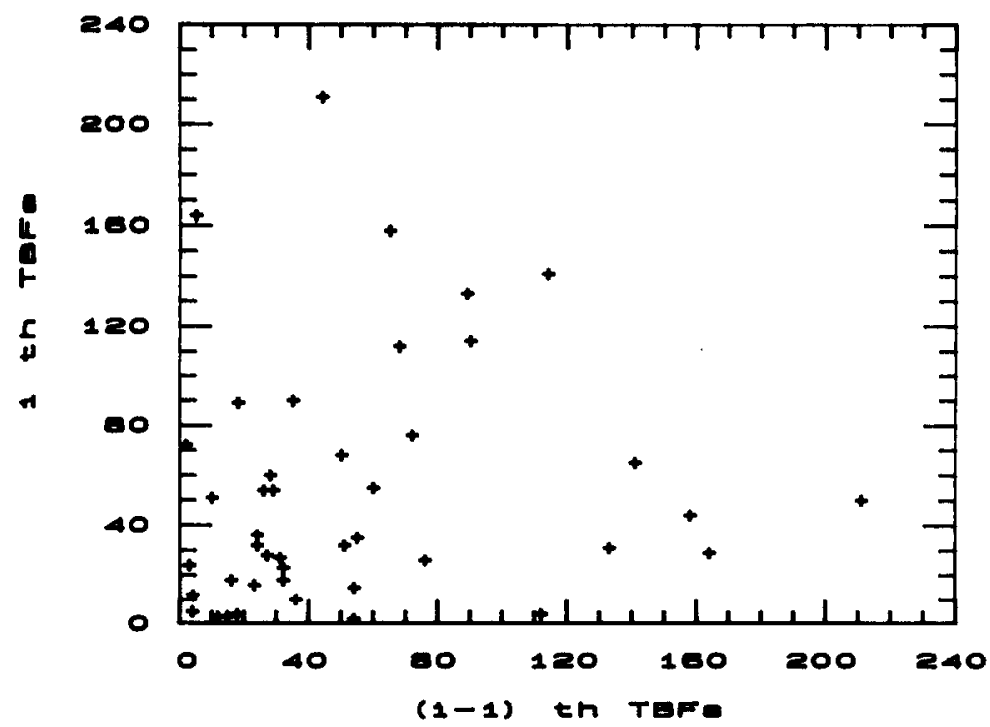

Fig. 6. Scatter plot of the $i$ th TBF against the $(i-1)$ th TBF $i=1,2, \ldots, n$. The TBFs are from LHD A. 


\subsection{Maximum-likelihood estimation}

As no trend or distinct serial correlations was observed during the exploratory analysis, the iid assumption for the data sets is not contradicted. Three life distributions namely exponential, Weibull and lognormal distributions were tried as possible candidates to describe the nature of TBFs distribution and the parameters were estimated by the ML method using STATGRAPHICS, a computer package for statistical analysis. Kolmogorov-Smirnov (K-S) test was used as a measure of goodness-of-fit of the different theoretical distributions. ${ }^{14}$ For this analysis, the TBFs are treated as complete samples. The results of the analysis of the TBFs for one machine are classified together with that of its subsystems in Table 1.

Similarly, by the study of TBFs of LHD B and LHD C and their subsystem, we find that in most of the cases the two parameter Weibull distribution provides the best-fit model for describing these data. The parameters of the Weibull distributions are estimated by the method of maximum-likelihood estimation (see Table 2).

\subsection{Analysis by TTT-plotting}

Besides analysing the TBFs for all the three LHD and their subsystems by the Kolmogorov-Smirnov test and ML method, TTT-plots were used to check the validity of the results obtained by the ML method and for obtaining the shape of the failure rate function. The TTT-plots of LHD A, B and $\mathrm{C}$ as a system are given in Figs 7,8 and 9, respectively.

The TBFs for the engine of all the three machines are analysed by using TTT-plots for three different situations namely when all the TBFs are treated as a complete sample, when the censored TBF is added to the following TBF; and when the TBF marked censored are dropped for the

TABLE 1

Results of Analysis with Kolmogorov-Smirnov Test for LHD A

\begin{tabular}{lcccl}
\hline \multirow{2}{*}{$\begin{array}{c}\text { System/ } \\
\text { subsystems }\end{array}$} & \multicolumn{3}{c}{ K-S statistics $D_{\max }$} & $\begin{array}{c}\text { Best-fit } \\
\text { model }\end{array}$ \\
\cline { 2 - 4 } & Exp. & Weibull & Lognormal & \\
\hline LHD & 0.081 & 0.069 & 0.118 & Weibull \\
Engine & 0.215 & 0.193 & 0.220 & Weibull \\
Brake & 0.125 & 0.101 & 0.110 & Weibull \\
Hydraulics & 0.200 & 0.198 & 0.180 & Lognormal \\
Transmission & 0.410 & 0.237 & 0.307 & Weibull \\
\hline
\end{tabular}


TABLE 2

ML Estimates of the Weibull Parameters

(scale parameter $=\alpha$, and shape parameter $=\beta$ )

\begin{tabular}{|c|c|c|c|c|c|c|}
\hline \multirow{2}{*}{$\begin{array}{c}\text { System/ } \\
\text { subsystems }\end{array}$} & \multicolumn{2}{|c|}{$L H D A$} & \multicolumn{2}{|c|}{$L H D B$} & \multicolumn{2}{|c|}{$L H D C$} \\
\hline & $\alpha$ & $\beta$ & $\alpha$ & $\beta$ & $\alpha$ & $\beta$ \\
\hline Machine & $54 \cdot 1$ & 1.07 & $48 \cdot 9$ & 1.02 & $42 \cdot 0$ & 0.86 \\
\hline Engine & $146 \cdot 4$ & $1 \cdot 35$ & $167 \cdot 1$ & $1 \cdot 17$ & $106 \cdot 0$ & $1 \cdot 15$ \\
\hline Brake & $77 \cdot 2$ & $1 \cdot 13$ & $216 \cdot 6$ & 1.06 & $67 \cdot 3$ & 0.91 \\
\hline Hydraulics & $221 \cdot 7$ & 0.97 & $128 \cdot 6$ & 1.08 & 138.9 & 1.01 \\
\hline Transmission & $282 \cdot 8$ & $2 \cdot 18$ & $127 \cdot 7$ & 0.65 & $138 \cdot 2$ & 1.01 \\
\hline
\end{tabular}

purpose of calculation. The TTT-plots of engine of LHD A for the above mentioned three situations are shown in Figs 10(a), 10(b) and 10(c). The TBFs of engines of all the three machines are also analysed by using double TTT-plots for gaining further insight into the data.

The TTT-plots of the brake, transmission and hydraulics system of LHD A are also presented in Figs 11,12 and 13, respectively. For analysis by TTTplotting, the TBFs of these subsystems are treated as complete samples.

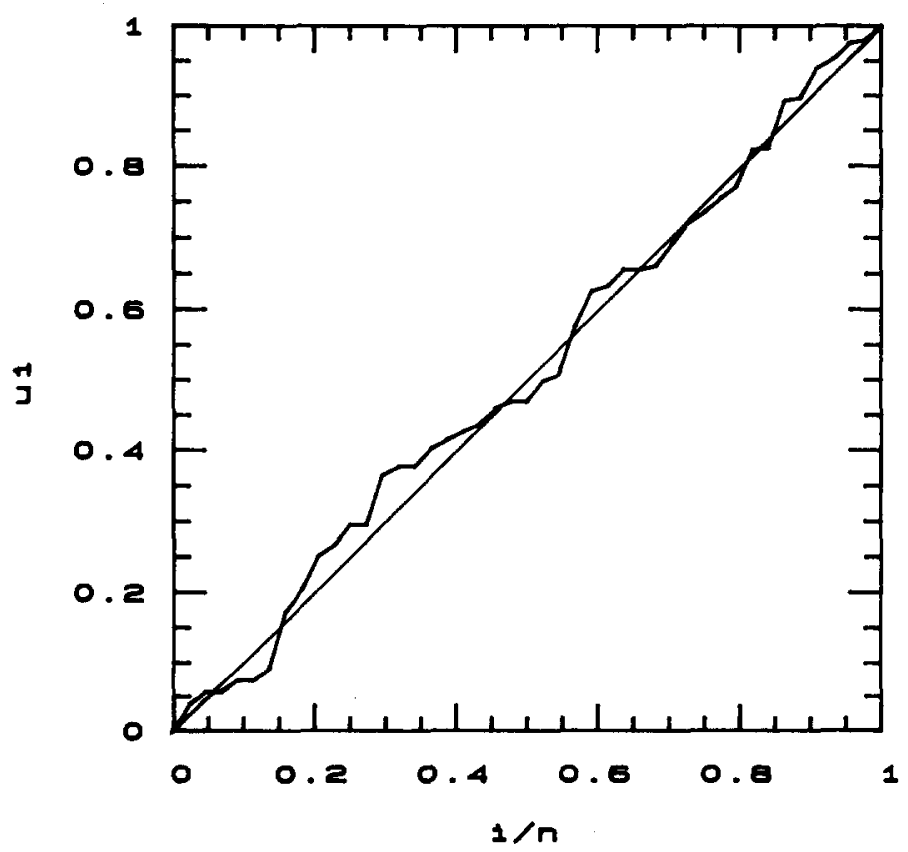

Fig. 7. The TTT-plot of LHD A. 


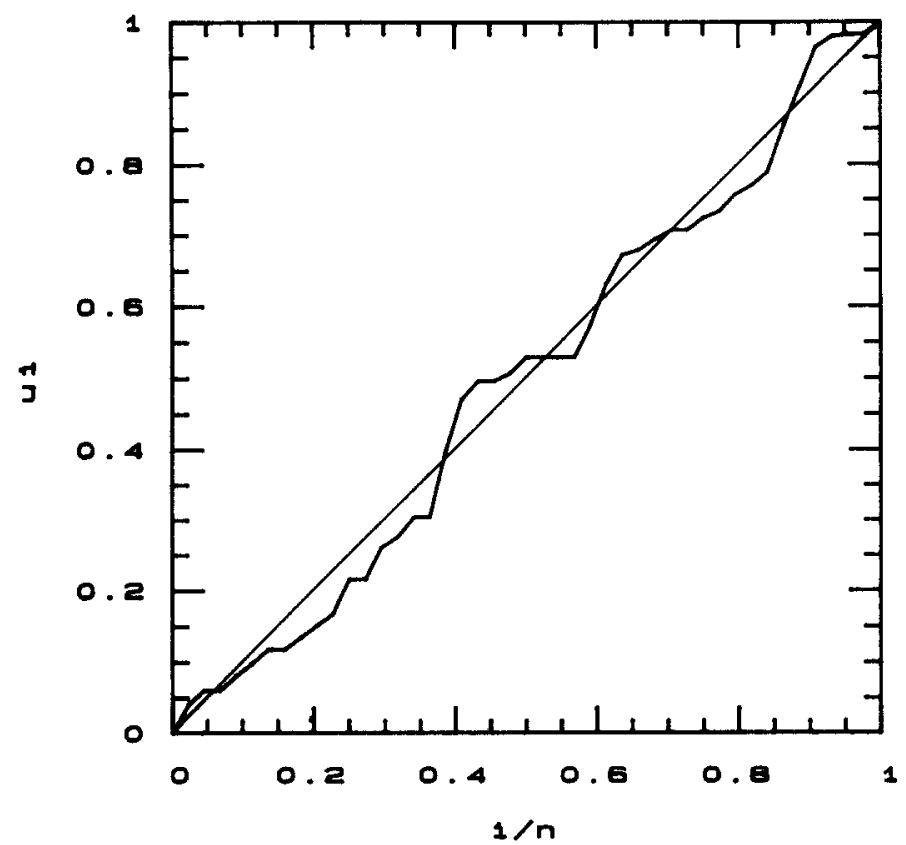

Fig. 8. The TTT-plot of LHD B.

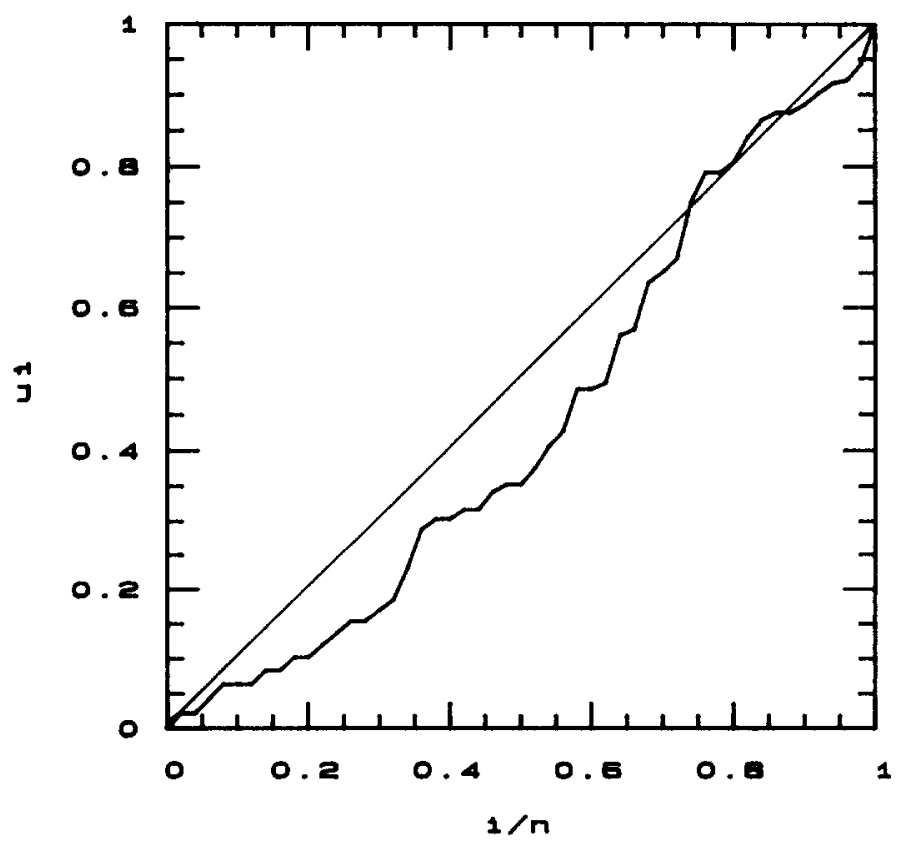

Fig. 9. The TTT-plot of LHD C. 


\section{DISCUSSION OF THE RESULTS}

(1) From the test for trend and serial correlation for the failure data of the LHD machines and other subsystems, it is clear that the assumption of iid is not valid for all the failure data. In our case at least four machines have shown the presence of trends. These machines are comparatively older in age. Besides, the presence of trends are more frequent in failures data of subsystems. However, most of the data set analysed have not contradicted the assumption of iid (see Figs 4, 5 and 6).

(2) From Table 2 and Figs 7, 8 and 9, it seems reasonable to assume that the TBFs of the machines as a whole are exponentially distributed illustrating the Drenick's theorem ${ }^{15}$ about the failure law of complex equipment. However, the Weibull distribution of LHD C has a shape parameter of 0.87 and also from the TTT-plot for this machine it is indicated that the TBFs follow a life distribution with decreasing failure rate (see Fig. 9).

(3) The TBFs for the engine of machine A exhibit an IFR (increasing failure rate) distribution because its TTT-plot indicates concave tendencies. ${ }^{3}$ This means that preventive maintenance is economical in this case. In such cases, the optimal maintenance interval by using an age repair model can be estimated by using TTT-plots. ${ }^{16}$ The IFR (increasing failure rate) observation is in agreement with the ML result in Table 2 where the shape parameter for the engine is 1.35 indicating increasing failure rate.

Furthermore, the double TTT-plots for the engine of LHD A indicate rather more clearly that the TBFs are iid with IFR characteristics because the points plotted in the double TTT-plots are randomly spread in the upper half of the unit squares (see Figs 14(a), 14(b) and 14(c)). ${ }^{10}$ Also the double TTT-plots for the engines of LHD B and LHD C indicate a similar pattern, but they are more weak and not very convincing.

(4) Brake and hydraulic systems of all the three LHD machines seem to have approximately constant failure rate as indicated by the TTTplots of these subsystems. These results are also in agreement with the ML estimation of the shape parameters of their respective TBFs (see Table 2 and Figs 11 and 12).

Further, since trend is noticed in the TBFs of the hydraulic system of LHD A as shown in Fig. 5, the assumption of iid is not justified. Thus, a non-stationary model like the non-homogeneous Poisson process (NHPP) model might be better than the renewal model. The 


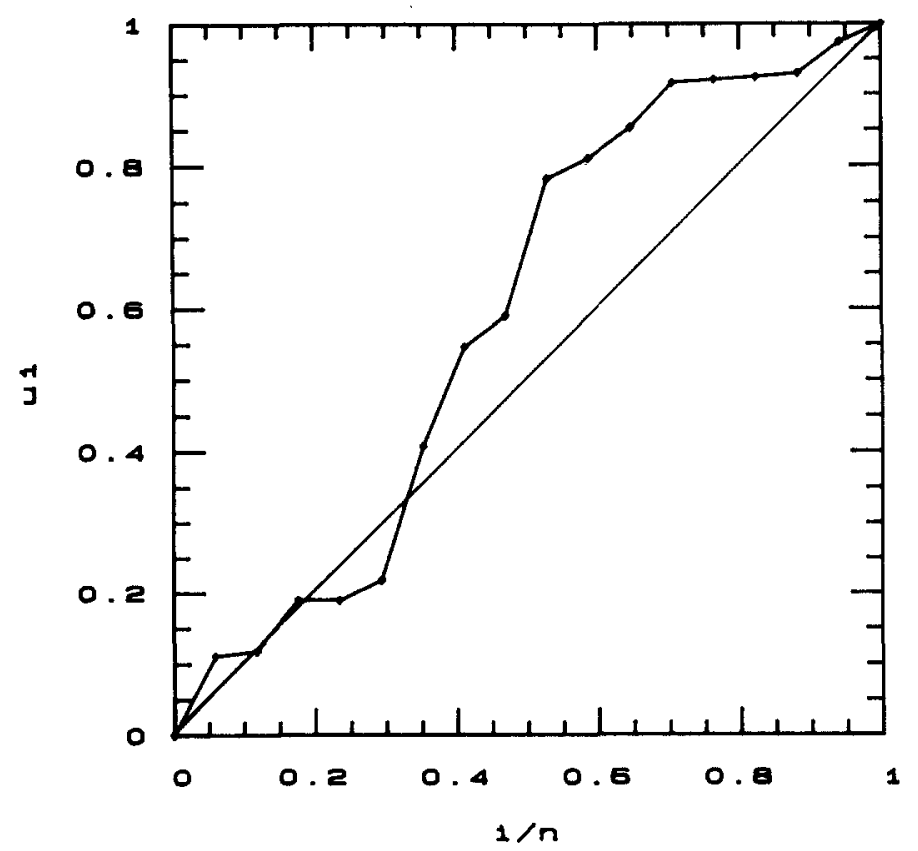

(a)

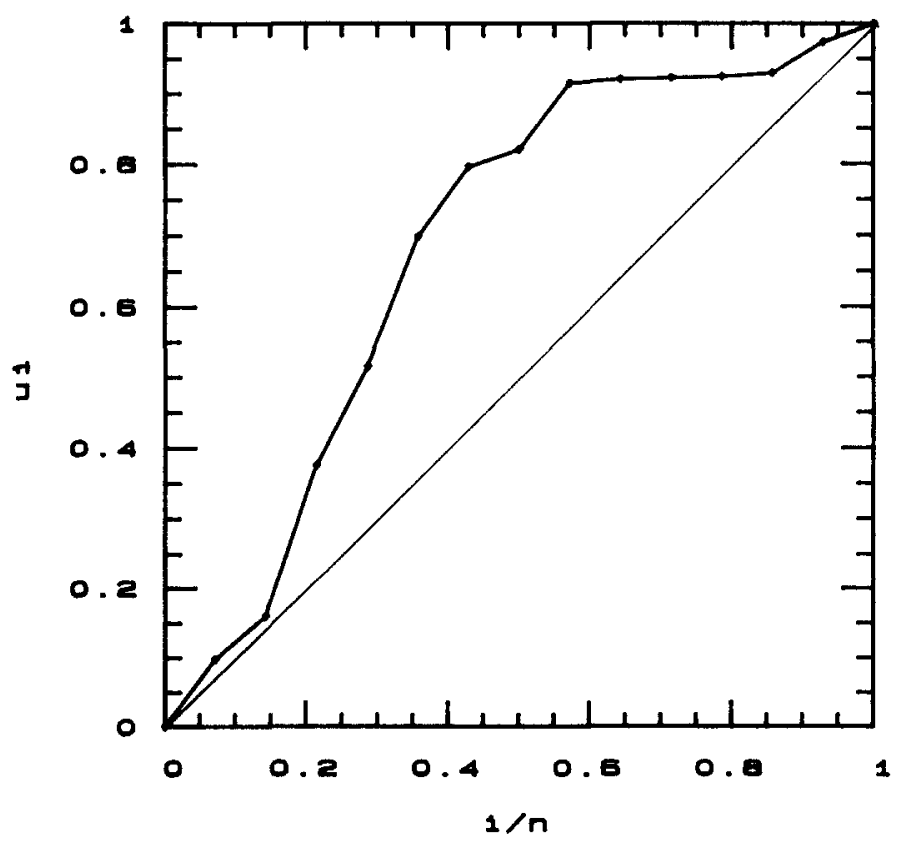

(b)

Fig. 10. TTT-plot of the engine of LHD A when censor time is (a) treated as failure time, (b) added to the following TBF. 


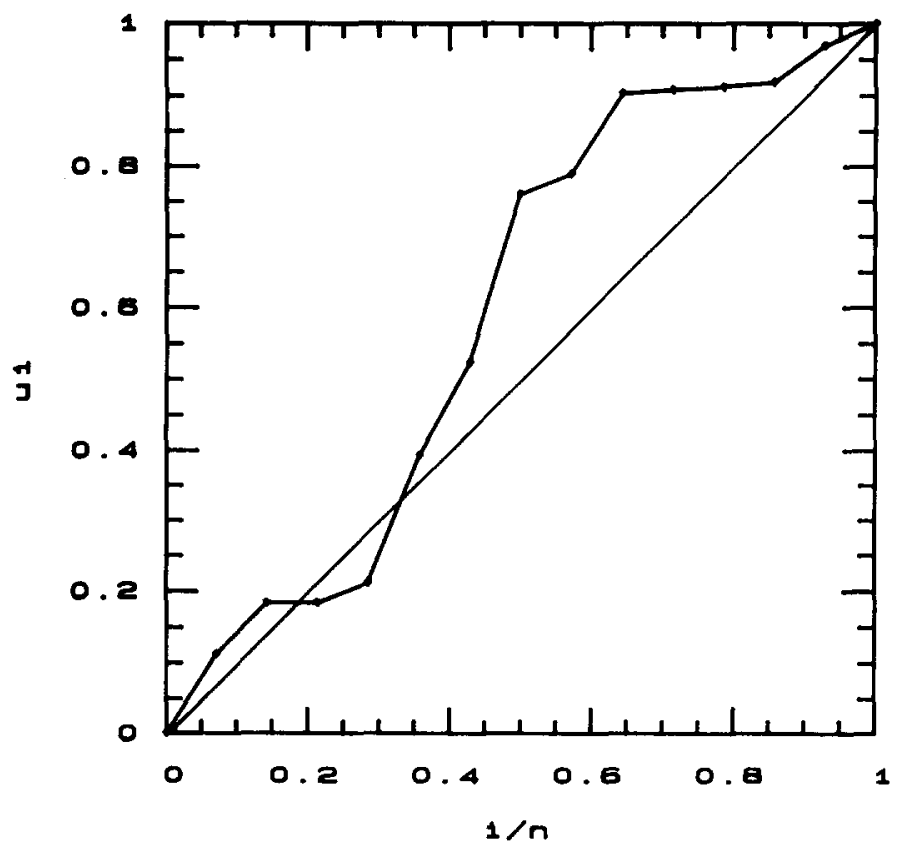

(c)

Fig. 10(c). TTT-plot of the engine of LHD A when censor time is discarded for the purpose of analysis.

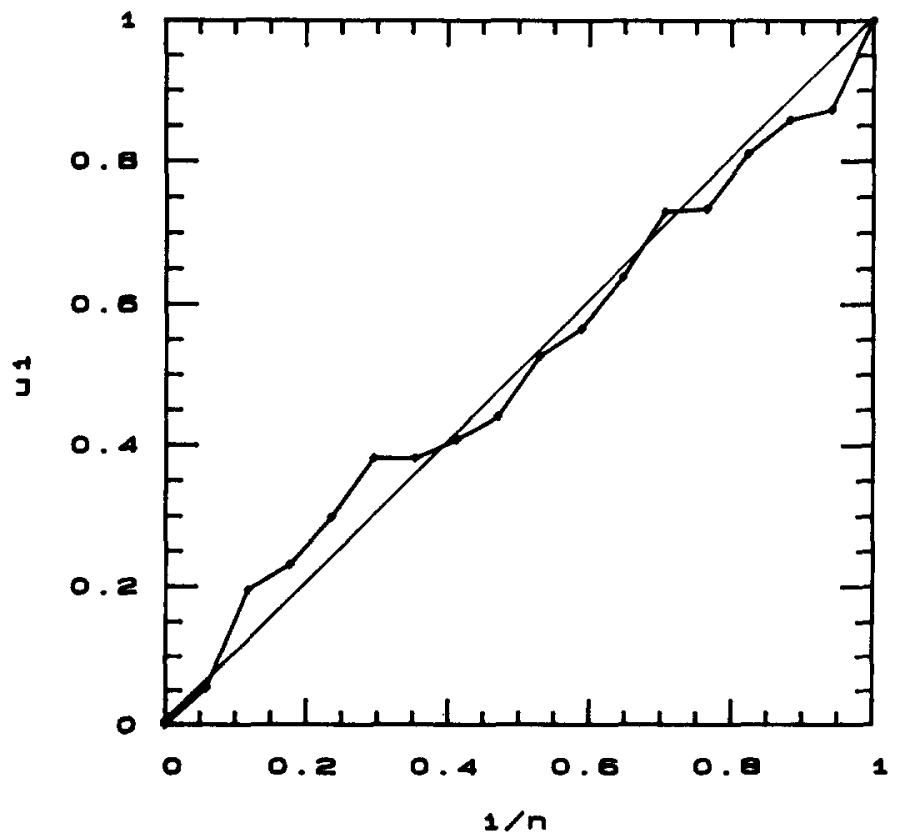

Fig. 11. The TTT-plot of the brake of LHD A. 


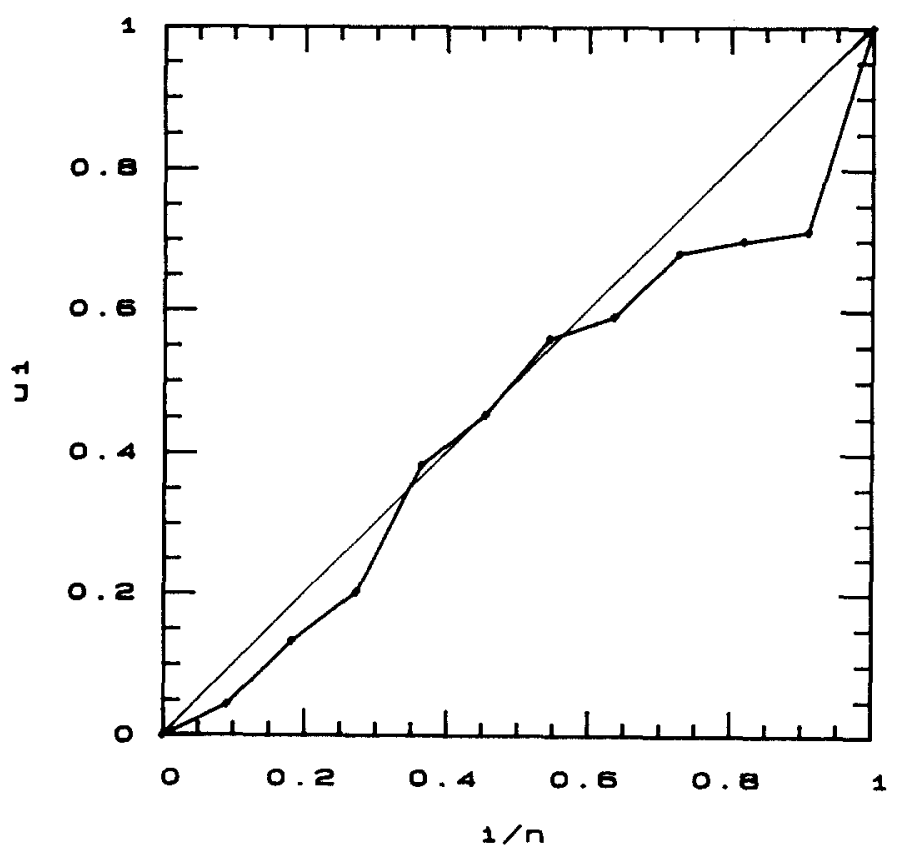

Fig. 12. The TTT-plot of the hydraulic system of LHD A.

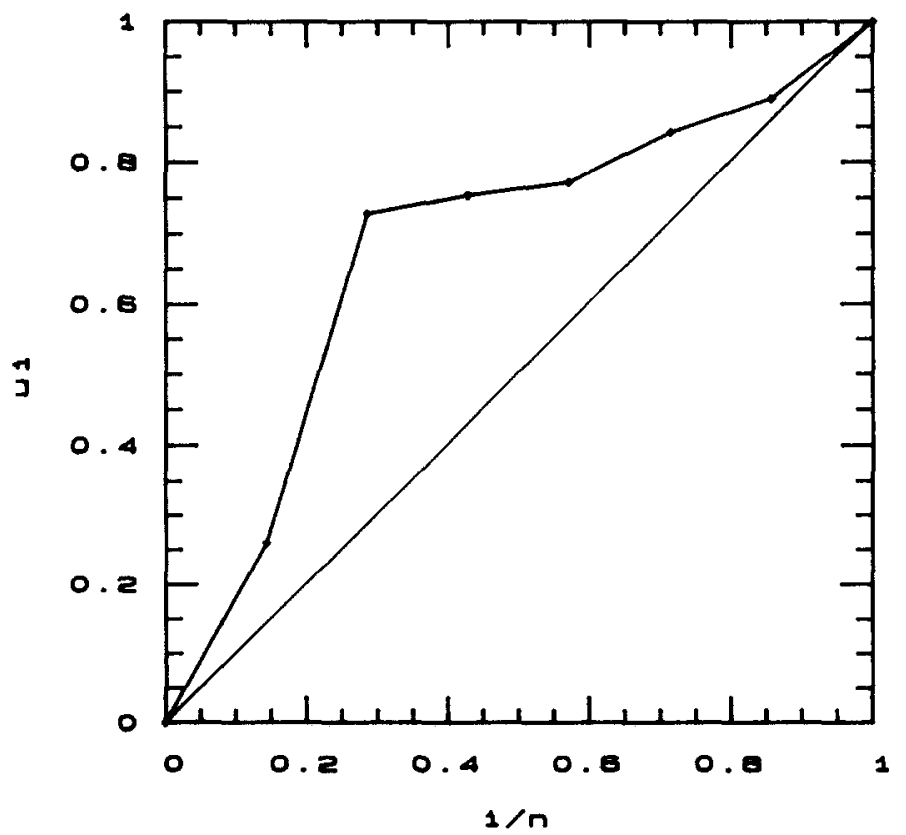

Fig. 13. The TTT-plot of the transmission of LHD A. 
most popular NHPP model is the power law process model where the failure intensity

$$
\lambda(t)=(\beta / \alpha)(t / \alpha)^{\beta-1}
$$

where $\beta$ and $\alpha$ are shape and scale parameters and can be estimated by the following expressions: ${ }^{17}$

$$
\begin{aligned}
& \alpha=t_{n} /(n)^{1 / \beta} \\
& \beta=n /\left(\sum_{i=1}^{n-1} \ln \left(t_{n} / t_{i}\right)\right)
\end{aligned}
$$

where $n$ is the number of failure events and the $t_{n}$ is the total running time and $t_{i}$ is the running time at the occurrence of failure number $i$, $i=1,2, \ldots, n$.

The value of $\beta$ in such a model for the hydraulic subsystem of LHD $A$ is obtained to 1.85 indicating that intensity of failure is increasing with age.

(5) Transmission of LHD A is showing a dominant IFR characteristic (see Table 2 and Fig. 13). However, those of machines $B$ and $C$ are DFR and exponential respectively in nature (see Table 2).

\section{CONSTRAINTS AND LIMITATIONS}

The major constraint of studies like this one is the availability of reliable and sufficient data. Collection of reliability data in mines for the mining machines is rare as compared to other industries. Further, if at all such data are available, they are not stored in a way so that it can be easily used for reliability analysis. But recently some of the world's leading mining companies have realized the advantages of such studies. They have started the collection of reliability data and have initiated various measures for their proper storage and fast retrieval.

\section{CONCLUSION}

Although, the reliability investigation is not yet finished, it seems that preventive maintenance of the engines of LHD machines could reduce the maintenance costs. Since we could not get the information about the maintenance cost, the suitable maintenance age is not yet estimated. 


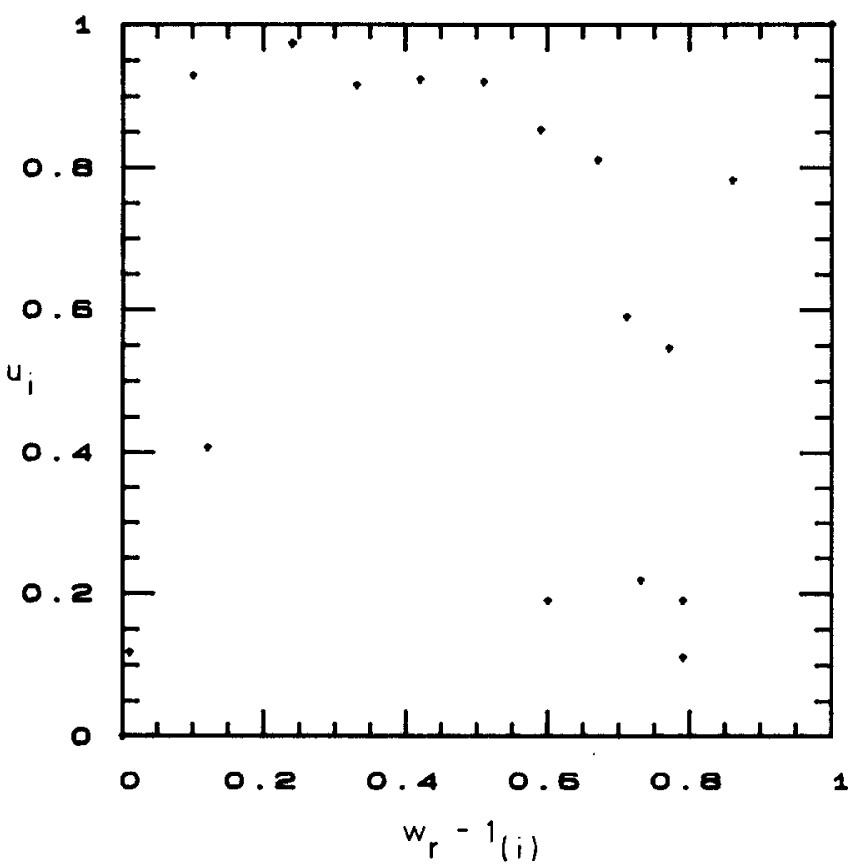

(a)

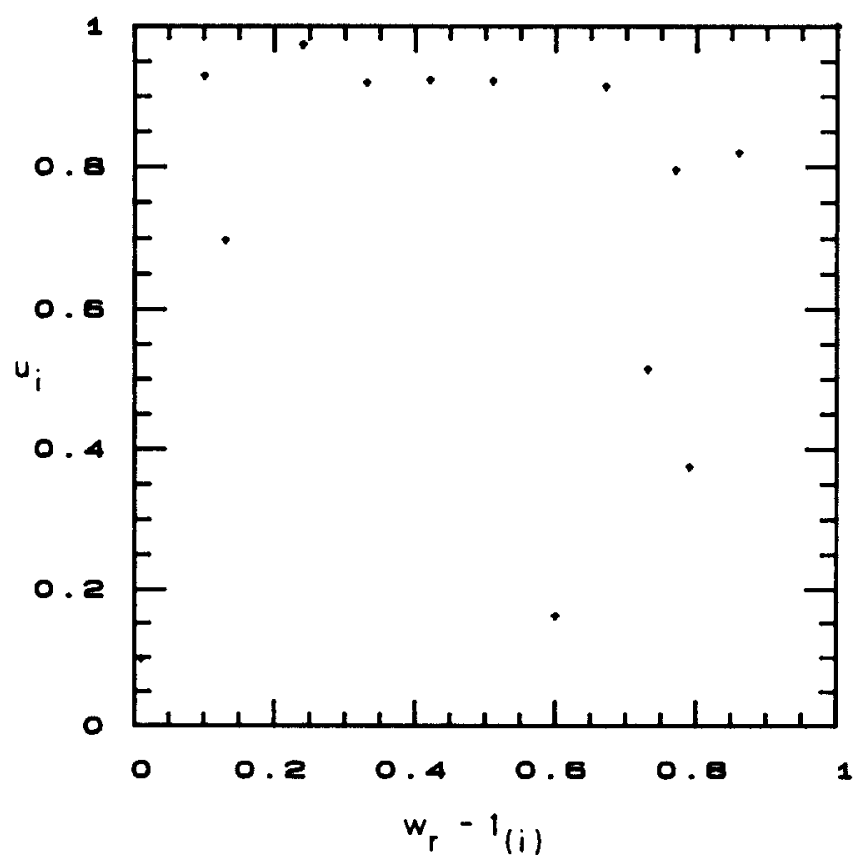

(b)

Fig. 14. The double TTT-plot of engine of LHD A (a) when censored TBFs are treated as failure time, (b) when the censored TBFs are added to the failure times which follow. 


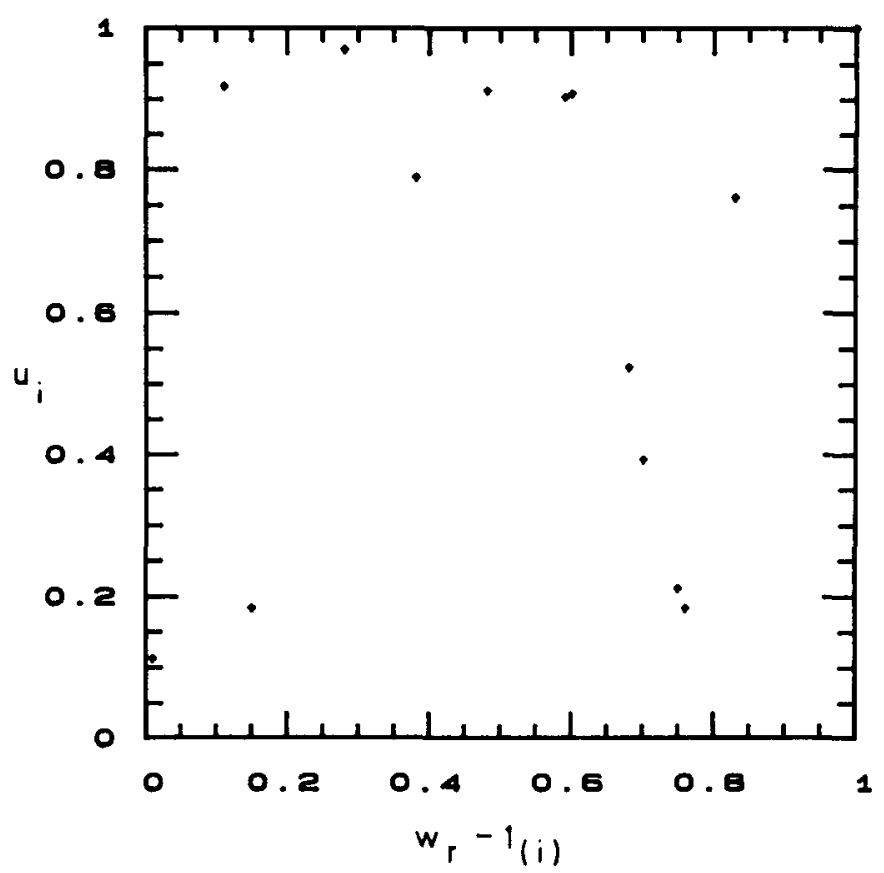

(c)

Fig. 14 contd. (c) when the censored TBFs are discarded.

This study has among other things shown that it is very important to explore the data sets for the presence of trends and serial correlation. Otherwise wrong conclusions can be drawn from the analysis.

Further, from the discussions of the results it is obvious that it is difficult to make any long term and general decision about the whole fleet based on the TBF data for one year. However this study has established that if data are available in sufficient quantity, decisions about the preventive maintenance can be taken. For mining industry, this type of studies can be of great help in reducing the steeply increasing cost of maintenance. Such studies are important keeping in view the present trends of automation in mines.

\section{ACKNOWLEDGEMENTS}

We are very thankful to Mr Per-Anders Akersten, Karlstad University, for his valuable comments and help in analysing the failure data especially through double TTT-plots. We also acknowledge our thanks to M/s LKAB, Kiruna Mines for providing data and other help during this study. 


\section{REFERENCES}

1. Danielson, B., Study of maintenance problems in Swedish mines (In Swedish). Status Report, Idhammar Konsultant AB, Sweden, 1987.

2. Nelson, W., Applied Life Data Analysis. John Wiley \& Sons, New York, 1982.

3. Barlow, R. E. \& Campo, R., Total time on test processes and applications to failure data analysis. In Reliability and Fault Tree Analysis, ed. R. E. Barlow, J. Fussel \& N. D. Singpurwalla. SIAM, Philadelphia, USA, 1975, pp. 451-81.

4. Bergman, B., Some graphical methods for maintenance planning. In Proceedings of 1977 Annual Reliability and Maintainability Symposium, Philadelphia, USA, pp. 468-71.

5. Klefsjö, B., On aging properties and the total time on test transform. Scandinavian J. Statistics, 9 (1982) 37-41.

6. Bergman, B. \& Klefsjö, B., The total time on test concepts and its use in reliability theory. Operations Research, 32 (1984) 596-606.

7. Bergman, B. \& Klefsjö, B., Burn-in models and TTT-transforms. Quality \& Reliability Engineering International, 1 (1985) 125-30.

8. Klefsjö, B., TTT-transforms - - a useful tool when analysing different reliability problems. Reliability Engineering, 15 (1986) 231-41.

9. Klefsjö, B., TTT-plotting-a tool for both theoretical and practical problems. Journal of Statistical Planning and Inference (in press).

10. Akersten, P. A., The bivariate TTT-plot-a tool for the study of non-constant failure intensities. In Proceedings of Society of Reliability Engineers Symposium, SRE' 86 Otaniemi, Finland, 1986.

11. Akersten, P. A., The double TTT-plot-a tool for the study of non-constant failure intensities. In Proceedings of Reliability '87, Birmingham, UK, pp. $2 \mathrm{~B} / 3 / 1-2 \mathrm{~B} / 3 / 8$.

12. Bendell, A. \& Walls, L. A., Exploring reliability data. Quality \& Reliability Engineering International, 1 (1985) 37-51.

13. Ascher, H. E. \& Feingold, H., Repairable System Reliability: Modelling, Inference, Misconceptions and Their Causes. Marcel Dekker, New York, 1984.

14. Levin, R. I., Statistics for Management. 3rd ed. Prentice-Hall, New Jersey, 1984.

15. Drenick, R. F., The failure law of complex equipment. J. Soc. Ind. \& Applied Mathematics, 8 (1960) 680-90.

16. Bergman, B. \& Klefsjö, B., A graphical method applicable to age replacement problems. IEEE-Transaction on Reliability, R-31 (1982) 478-81.

17. Crow, L. H., Reliability analysis for the complex repairable systems. In Reliability and Biometry, ed. F. Proschan \& R. J. Serfling. SIAM, Philadelphia, USA, 1974, pp. 379-410. 


\section{APPENDIX 1}

\section{The TTT-plot}

Suppose that $0=t_{(0)} \leq t_{(1)} \cdots \leq t_{(n)}$ is an ordered sample of times to failure of a unit and let

$$
S_{i}=n t_{(1)}+(n-1)\left(t_{(2)}-t_{(1)}\right)+\cdots+(n-i+1)\left(t_{(i)}-t_{(i-1)}\right)
$$

(and $S_{0}=0$ ) denote the total time on test (TTT) at time $t_{(i)}, i=1,2, \ldots n$.

The TTT-plot is obtained by plotting $\left(i / n, u_{i}\right), i=0,1,2, \ldots, n$ where $u_{i}=S_{i} / S_{n}$, and connecting the plotted points by the line segments.

The TTT-plot and its asymptotic counterpart, the scaled TTT-transform were first presented by Barlow and Campo. ${ }^{3}$ Further applications of these tools have been presented in a number of papers by Bergman and Klefsjö. ${ }^{6.7 .16}$

\section{The double TTT-plot}

Let us assume that a repairable system is studied under the time interval $[0, T]$ and that $n$ failures have occurred at times

$$
X_{1}=t_{1}, X_{2}=t_{1}+t_{2}, \ldots, X_{n}=t_{1}+t_{2}+\cdots+t_{n}
$$

Thus, the normalized event times are $w_{i}=X_{i} / T, i=1,2, \ldots, n$. Furthermore, the rank variables $r(i), i=1,2, \ldots, n$, are defined by

$$
t_{(r(i))}=t_{i} \quad i=1,2, \ldots, n
$$

and the reverse rank variables $r^{-1}(i), i=1,2, \ldots, n$, are defined by

$$
t_{r^{-1}(i)}=t_{(i)} \quad i=1,2, \ldots, n
$$

The double TTT-plot is obtained by plotting

$$
\left(w_{r-1}(i), u_{i}\right) \text { for } i=1,2, \ldots, n
$$

where $u_{i}$ is the quantity plotted in the usual TTT-plots.

If the successive failure times are independent and exponentially distributed, the points plotted in the double TTT-plot are randomly spread in the unit square. Different deviations from this random pattern indicate that other models than the homogeneous Poisson process are more suitable. ${ }^{10,11}$

\section{APPENDIX 2}

The time between successive failures (TBFs) for three machines and their major subsystems are presented below in Tables B1, B2 and B3. 
TABLE B1

Time Between Failures (TBFs) in Hours and Reasons for Failures

\begin{tabular}{|c|c|c|c|c|c|c|}
\hline \multirow{2}{*}{$\begin{array}{l}\text { Ser. } \\
\text { No. }\end{array}$} & \multicolumn{2}{|c|}{$L H D A$} & \multicolumn{2}{|c|}{$\angle H D B$} & \multicolumn{2}{|c|}{$\angle H D C$} \\
\hline & $T B F$ & $\begin{array}{l}\text { Subsystem } \\
\text { repaired }\end{array}$ & $T B F$ & $\begin{array}{l}\text { Subsystem } \\
\text { repaired }\end{array}$ & $T B F$ & $\begin{array}{c}\text { Subsystem } \\
\text { repaired }\end{array}$ \\
\hline 1 & 16 & EHO & 149 & $T$ & 110 & $\mathrm{~B}^{a}$ \\
\hline 2 & 23 & B & 33 & $\mathrm{~A} T \mathrm{Tr}$ & 13 & $\mathrm{~B}$ \\
\hline 3 & 32 & B & 08 & $\mathrm{ATr}$ & 72 & $\operatorname{Tr} \mathrm{A}$ \\
\hline 4 & 24 & B & 05 & $\operatorname{Tr} \mathrm{HO}^{a}$ & 04 & $\mathrm{~B}$ \\
\hline 5 & 03 & $\mathrm{~T}$ & 31 & $\operatorname{Tr}$ & 45 & $\mathrm{~A} \operatorname{TrO}$ \\
\hline 6 & 12 & B & 12 & $\mathrm{H}$ & 56 & $\mathrm{~T}$ \\
\hline 7 & 04 & B & 188 & HTEO & 19 & $B O E^{a}$ \\
\hline 8 & 112 & $\mathrm{E}$ & 02 & $\mathrm{~T}$ & 27 & $\mathrm{~B} \operatorname{Tr} \mathrm{A}$ \\
\hline 9 & 68 & EHA & 36 & $\mathrm{~B}$ & 36 & B \\
\hline 10 & 50 & $\operatorname{Tr}$ & 63 & $\mathrm{E}$ & 90 & B \\
\hline 11 & 211 & EHTr & 53 & $E$ & 19 & EO \\
\hline 12 & 44 & $\mathrm{~T}$ & 56 & HB & 07 & $\mathrm{Tr}$ \\
\hline 13 & 158 & $\mathrm{E} \operatorname{Tr} \mathrm{O}$ & 06 & $\mathrm{~T}$ & 02 & $B E$ \\
\hline 14 & 65 & $\mathrm{Tr}$ & 04 & $\mathrm{H}$ & 118 & $\mathrm{BE}$ \\
\hline 15 & $14 i$ & $\mathrm{EBO}$ & 147 & $\mathrm{H}$ & 44 & $\mathrm{EO}$ \\
\hline 16 & 114 & B & 36 & EHO & 08 & $\operatorname{Tr}$ \\
\hline 17 & 90 & EBO & 04 & $\mathrm{ETr}$ & 277 & $\mathrm{EBO}^{a}$ \\
\hline 18 & 35 & B & 76 & $\mathbf{T}$ & 04 & B \\
\hline 19 & 55 & 0 & 36 & B & 08 & $\mathrm{E}$ \\
\hline 20 & 60 & $\mathrm{Tr}$ & 36 & $\mathrm{~B}$ & 10 & $\mathbf{H}$ \\
\hline 21 & 28 & $\mathrm{EBHA}^{a}$ & 61 & E B & 79 & $\operatorname{Tr}$ \\
\hline 22 & 27 & & 48 & $\mathrm{~T}$ & 103 & $\mathrm{E}$ \\
\hline 23 & 30 & B & 58 & $T$ & 06 & $\mathrm{Tr}$ \\
\hline 24 & 134 & $\mathrm{ETr} B \mathrm{H}$ & 68 & $\mathrm{OHEB} \mathrm{B}^{a}$ & 18 & $\operatorname{Tr}$ \\
\hline 25 & 89 & B & 03 & $T$ & 147 & $\mathrm{EH}$ \\
\hline 26 & 18 & BHE & 12 & $\mathrm{H}$ & 96 & $H$ \\
\hline 27 & 32 & EHB & 33 & $\mathrm{~T}$ & 22 & $\mathrm{ETr}$ \\
\hline 28 & 51 & $\mathrm{HB}$ & 07 & $\mathrm{~T}$ & 03 & $\mathrm{Tr}$ \\
\hline 29 & 10 & $\mathrm{H}$ & 71 & $\mathrm{EH}$ & 24 & $\operatorname{Tr} \mathbf{H}$ \\
\hline 30 & 36 & ET & 149 & EOH & 03 & $\mathrm{ETr}$ \\
\hline 31 & 24 & $\operatorname{Tr} B$ & 06 & $\mathrm{E}$ & 09 & $T$ \\
\hline 32 & 03 & $\mathrm{E}$ & 54 & $\mathrm{Tr}$ & 99 & HE \\
\hline 33 & 15 & $O E$ & 09 & $\operatorname{Tr}$ & 82 & ETH \\
\hline 34 & 54 & $\mathrm{H}$ & 115 & $\operatorname{Tr} B^{a}$ & 121 & 0 \\
\hline 35 & 26 & $\mathrm{O}$ & 58 & $\mathrm{E}$ & 54 & $\mathrm{HO}$ \\
\hline 36 & 76 & $\mathrm{E}$ & 96 & $\mathrm{H}$ & 79 & $\mathrm{EHTr}$ \\
\hline 37 & 72 & $\mathrm{~T}$ & 18 & $\mathrm{~T}$ & 99 & A \\
\hline 38 & 02 & $\mathrm{H}$ & 16 & $\mathrm{OHE}$ & 18 & $\mathrm{H}$ \\
\hline 39 & 54 & $\mathrm{~B} \operatorname{Tr} \mathrm{O}^{a}$ & 25 & $\mathrm{H}$ & 05 & $E$ \\
\hline 40 & 29 & $\mathrm{~T}$ & 139 & $\mathrm{ABT}^{a}$ & 21 & HE \\
\hline 41 & 164 & ЕTHO & 18 & $\operatorname{Tr}$ & 01 & $\mathrm{~T}$ \\
\hline 42 & 04 & $\mathrm{~T}$ & 34 & $\mathrm{E} \operatorname{Tr} B$ & 03 & $\mathrm{H}$ TrO \\
\hline 43 & 04 & $\mathrm{~T}$ & 15 & $\mathrm{OHTr}$ & 05 & $\mathrm{H}$ \\
\hline 44 & 18 & $\mathrm{~T}$ & 41 & $\operatorname{Tr} \mathrm{H}$ & 01 & $\mathrm{~T}$ \\
\hline 45 & & & & & 59 & $\mathrm{HO}$ \\
\hline 46 & & & & & 22 & $E$ \\
\hline 47 & & & & & 17 & EH \\
\hline 48 & & & & & 35 & $O B H^{a}$ \\
\hline 49 & & & & & 35 & E B \\
\hline 50 & & & & & 29 & B \\
\hline
\end{tabular}

$\mathrm{E}=$ Engine; $\mathrm{H}=$ Hydraulics; $\mathrm{Tr}=$ Transmission; $\mathrm{T}=$ Tyres and wheels; $\mathrm{O}=$ Others inclusive of body, cabin, chassis, etc.; $\mathbf{A}=$ Airconditioning; ${ }^{a}$ maintenance. 

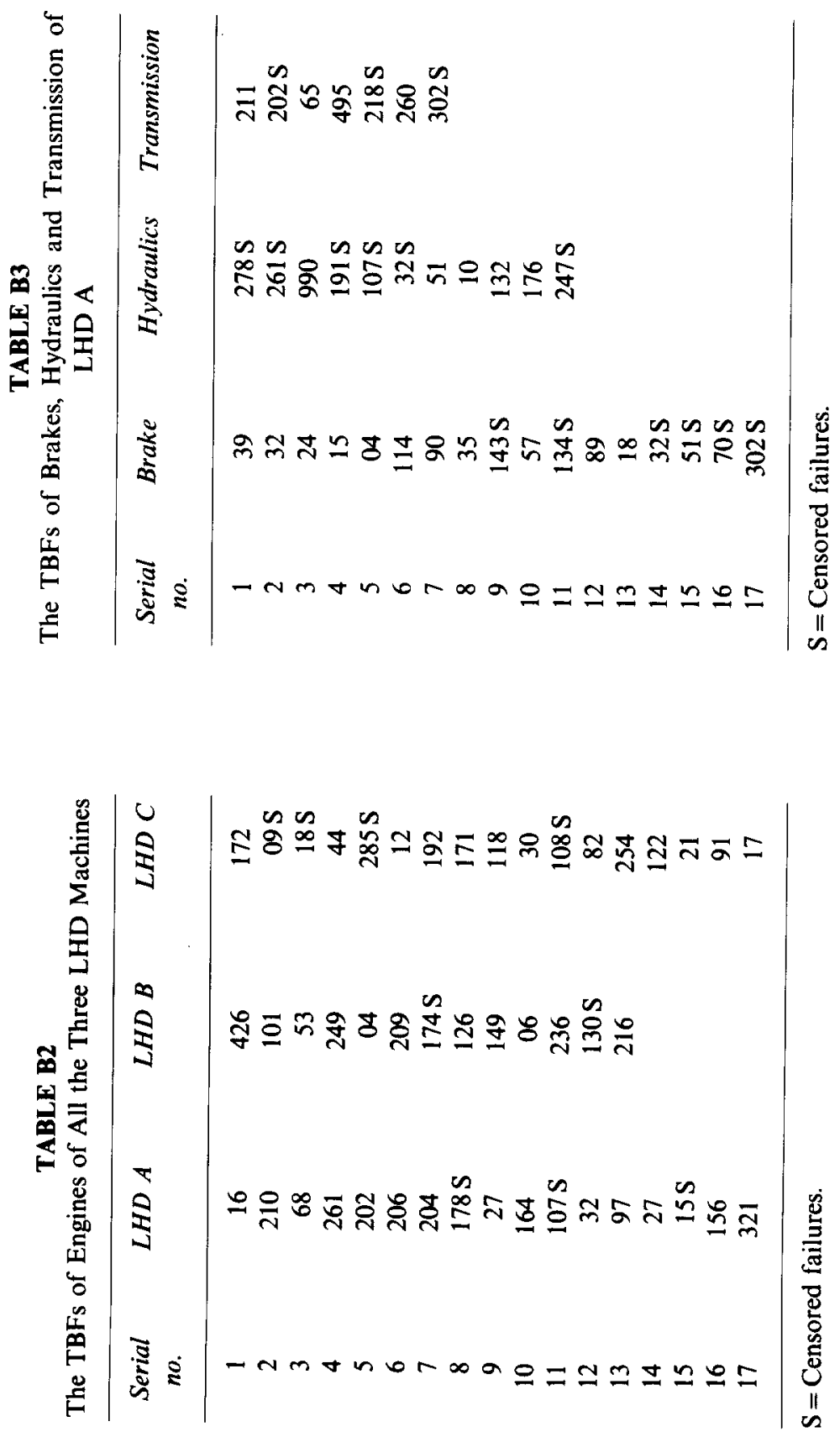